\title{
Deodorizing Methods for Recycled High-density Polyethylene Plastic Wastes
}

\author{
HO DANY ${ }^{1}$, WONG WHUI DHONG ${ }^{1}$, KOH WENG JIAT ${ }^{1}$, TAN KIANT LEONG ${ }^{1}$, \\ NOR YULIANA YUHANA ${ }^{1 *}$, GILBERT TAN ${ }^{2}$ \\ ${ }^{1}$ Program of Chemical Engineering, Department of Chemical and Process Engineering, Faculty of Engineering \& Built \\ Environment, Universiti Kebangsaan Malaysia, Bangi, Malaysia \\ ${ }^{2}$ Green Concept Technology Sdn. Bhd., Lot P.T 14277, Jalan Perusahaan 26, Kaw.11, Jalan Banting, Pandamaran, 42000 \\ Pelabuhan Klang, Selangor Darul Ehsan, Malaysia
}

\begin{abstract}
The recycling of high-density polyethylene plastic (HDPE) plays a crucial role in sustainable development. However, obstacles to the use of recycled HDPE remain because of the material and processing properties and odors of recycled HDPE. The odor of recycled detergent bottle plastic leads to rejection by most detergent manufacturers. Recently, some recycling enterprises have adapted recycling with odor reduction processes involving the use of solvents, antimicrobial additives, and odor extraction units in feeders and extruders. However, these processes may affect the quality and cost of recycled plastic. Most small and medium businesses (SMBs) may not favor these effects due to their limited models and resources. In addition, most SMBs are unwilling to replace their current recycling operation units. Hence, this study aimed to find alternative and economical ways for odor reduction in the recycling process. A modification of the recycling process was introduced in the pretreatment of plastic flakes before entry into the feeder of an extrusion unit. The effect of selected washing temperatures, i.e., $65^{\circ} \mathrm{C}, 75^{\circ} \mathrm{C}, 85^{\circ} \mathrm{C}$, and $95^{\circ} \mathrm{C}$, on the removal of odor from recycled $\mathrm{HDPE}$ was further studied. The addition of sodium bicarbonate, calcium carbonate, and citric acid into a heated water bath enhanced the deodorizing effect. The relationship of these three chemicals with the deodorization of HDPE plastics was investigated through sensory evaluation. Lastly, the potential of the deodorized recycled HDPE for resin pellet production and commercialization were investigated.
\end{abstract}

Keywords: High-density polyethylene (HDPE), recycling process, economical, deodorizing, sustainable

\section{Introduction}

Over the last 11 years, the plastics industry has become one of Malaysia's most varied and vibrantly growing industries, showing an average growth rate of 15\% [1]. Malaysia began purchasing recycled plastic from China in 2017 after China banned plastic imports. Discarded plastic contains 24 recyclable and solid waste forms [2]. The growth of imported plastic waste has increased the recycling industry's production. Recycled high-density polyethylene (HDPE) can be categorized into HDPE natural and HDPE mix. HDPE recycling processes are commonly used in manufacturing domestic goods, such as bottles, cans, toys, helmets, piping, and recycling bins. For detergent manufacturers, the cost of recycled HDPE is considerably lower than that of virgin HDPE. However, we face the problem of eliminating the bad odor of HDPE during recycling. Odor-control recycling technologies are complicated and costly and thus cannot be afforded by SMEs. Moreover, they may affect the consistency of the plastic being recycled. New technologies are required to improve HDPE recovery. This study aimed to examine the deodorization of recycled HDPE through treatment with sodium bicarbonate, calcium carbonate, and citric acid in a water bath at various temperatures.

Sodium bicarbonate, also known as baking soda, is used as an effective adsorbent in the odor treatment of recycled HDPE to remove various undesirable substances, such as volatile and toxic compounds [3]. Sodium citrate, which is obtained from the reaction between sodium bicarbonate and citric acid, is another odor neutralizer that is useful for eliminating bad smells by balancing $p \mathrm{H} \mathrm{[4].}$

*email: yuliana@ukm.edu.my 
Calcium carbonate, also known as limestone, has the capability to mask odor and pungency [5].

\section{Materials and methods}

\subsection{Preparation of samples}

HDPE materials were supplied by KA Plastic Enterprise. HDPE natural plastics originate from milk and sauce bottles and are primarily used to contain food. HDPE mix is derived from detergent and shampoo bottles. KA Plastic Enterprise is a company whose task is to collect, sort, and crush recycled plastics. A total of $25 \mathrm{~g}$ each of HDPE mix and HDPE natural flakes was weighed out and then cold washed with regular stirring in $500 \mathrm{~mL}$ of water to remove soil. The plastics were then rinsed off and filtered out.

\subsection{Early Stage of investigation}

The best temperature and time for hot washing to remove the odor retained in HDPE plastics were observed. The cold-washed plastics were subjected to hot washing in $500 \mathrm{~mL}$ of water at $65^{\circ} \mathrm{C}$ for 10 min. After 10min, the plastics were rinsed and then transferred into a tank equipped with a blower for $20 \mathrm{~min}$ of drying. The temperature of the tank was approximately $40^{\circ} \mathrm{C}-50^{\circ} \mathrm{C}$. The experiments were repeated by varying the temperatures of the hot-washing section to $75^{\circ} \mathrm{C}, 85^{\circ} \mathrm{C}$, and $95^{\circ} \mathrm{C}$. Then, the whole experiments were repeated on both types of plastics with $15 \mathrm{~min}$ of hot washing at each temperature. The dried plastic samples were collected and analyzed through sensory evaluation. The best results for the temperature and duration for hot washing were chosen after inspection.

\subsection{Chemical treatment}

Three chemicals, namely, sodium bicarbonate, calcium carbonate, and citric acid, were chosen to remove odors from recycled HDPE. A total of $20 \mathrm{~g}$ of sodium bicarbonate was weighed out and poured into $500 \mathrm{~mL}$ of water before the plastics were subjected to hot washing. The plastics were immersed in the solution and then hot washed. After the selected duration, the plastics were rinsed and dried. The dried samples were collected and examined. The experiments were repeated by using calcium carbonate and a combination of sodium bicarbonate and citric acid.

\subsection{Parameter measurements}

\subsubsection{Sensory evaluation}

The panel members who participated in the experiment were well educated on the sensory properties of HDPE plastics. A trained panel of 15 members, including researchers from this investigation, examined the plastic HDPE samples before and after treatment. A scale of 1-5 was used in this investigation, with 1 indicating undesirability and 5 indicating outstanding odor reduction. The rating score for each sample was finalized by obtaining an average score for each sample from the panel members.

\subsubsection{Scanning electron microscopy and energy dispersive $X$-ray analysis}

Scanning electron microscopy (SEM) was used to analyze the surface morphology of HDPE plastic samples before and after treatment. Energy dispersive X-ray (EDX) analysis coupled with SEM was performed on the selected HDPE plastic samples to characterize the composition of the samples. The data generated by EDX analysis consisted of spectra showing peaks that corresponded to the elements. The true composition of the sample could be analyzed on the basis of the data.

\subsubsection{Fourier-transform infrared spectroscopy analysis}

Fourier transform infrared spectroscopy (FTIR) analysis was performed to obtain an infrared spectrum of the absorption or emission of organic and polymeric materials. It was used to characterize the chemical composition on the surface of the selected HDPE samples. The presented spectrum, which 
encompassed the wavelength range of $4000 \mathrm{~cm}^{-1}$ to $500 \mathrm{~cm}^{-1}$, was used to represent the molecular fingerprint of the samples.

\section{Results and discussions}

The odor reduction level was determined by using a rating system with scores of 1 to 5 provided by each team member. Next, the rating score for each sample was finalized by obtaining an average score from each of the 15 panel members. The highest score indicated the best odor reduction level for the HDPE plastic samples.

Table 1. Average scores of odor reduction level based on different temperatures and washing time using water only in hot washing section

( $1=$ Strong Odors, $5=$ Weak Odors after treatment)

\begin{tabular}{|c|c|c|c|c|}
\hline \multirow{2}{*}{$\begin{array}{c}\text { Time } \\
\text { (minutes)/ Temperature }\left({ }^{\circ} \mathrm{C}\right)\end{array}$} & \multicolumn{3}{|c|}{ Average scores of an odor reduction level } \\
\cline { 2 - 5 } & \multicolumn{2}{|c|}{ HDPE Natural } & $10 \mathrm{~min}$ & $15 \mathrm{~min}$ \\
\cline { 2 - 5 } & $10 \mathrm{~min}$ & $15 \mathrm{~min}$ & 1.00 & 1.00 \\
\hline 65 & 1.00 & 1.00 & 1.00 & 1.70 \\
\hline 75 & 2.30 & 2.00 & 1.00 & 1.30 \\
\hline 85 & 1.30 & 1.70 & 1.30 & 2.00 \\
\hline 95 & 2.70 & 2.30 & HDPE Mix \\
\hline
\end{tabular}

Table 2. Average odor reduction scores based on different chemicals used in $95^{\circ} \mathrm{C}$ hot water for HDPE Natural and HDPE Mix in 10 and 15 min, respectively.

( $1=$ Strong Odors, $5=$ Weak Odors after treatment)

\begin{tabular}{|c|c|c|}
\hline \multirow{2}{*}{ Type of Chemicals/ Type of plastic } & \multicolumn{2}{|c|}{ Average odor reduction scores } \\
\cline { 2 - 3 } & HDPE Natural & HDPE Mix \\
\hline Sodium bicarbonate & 3.00 & 2.70 \\
\hline Calcium carbonate & 4.00 & 2.30 \\
\hline Sodium bicarbonate with added citric acid & 3.80 & 4.00 \\
\hline
\end{tabular}

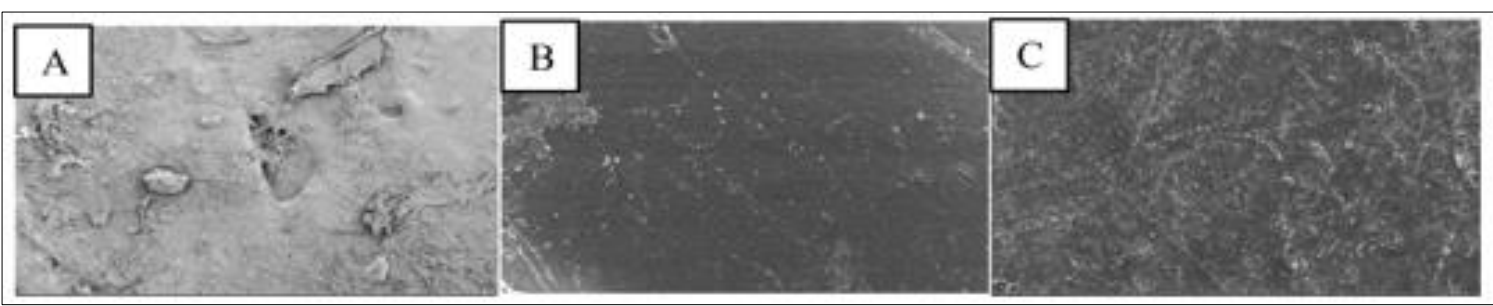

Figure 1. SEM images of surface morphology of HDPE Natural Plastic flake under 50X magnifying power: A) Unwashed, B) cold wash only C) cold wash $10 \mathrm{~min}$ and hot wash $10 \mathrm{~min}$ at $95^{\circ} \mathrm{C}$ with added $40 \mathrm{~g} / \mathrm{L}$ calcium carbonate

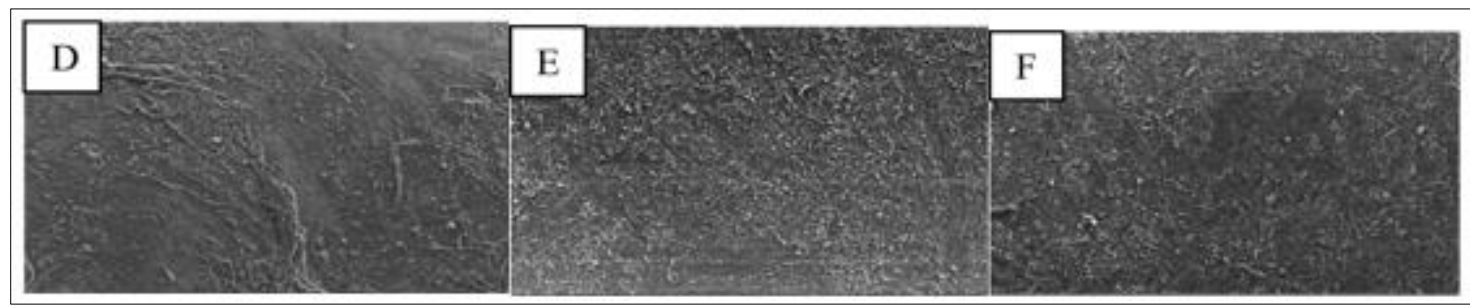

Figure 2. SEM images of surface morphology of HDPE Mix Plastic flake under 50X magnifying power: D) Unwashed, E) Cold wash only F) cold wash $10 \mathrm{~min}$ and hot wash $15 \mathrm{~min}$ at $95^{\circ} \mathrm{C}$ with added $40 \mathrm{~g} / \mathrm{L}$ sodium bicarbonate 


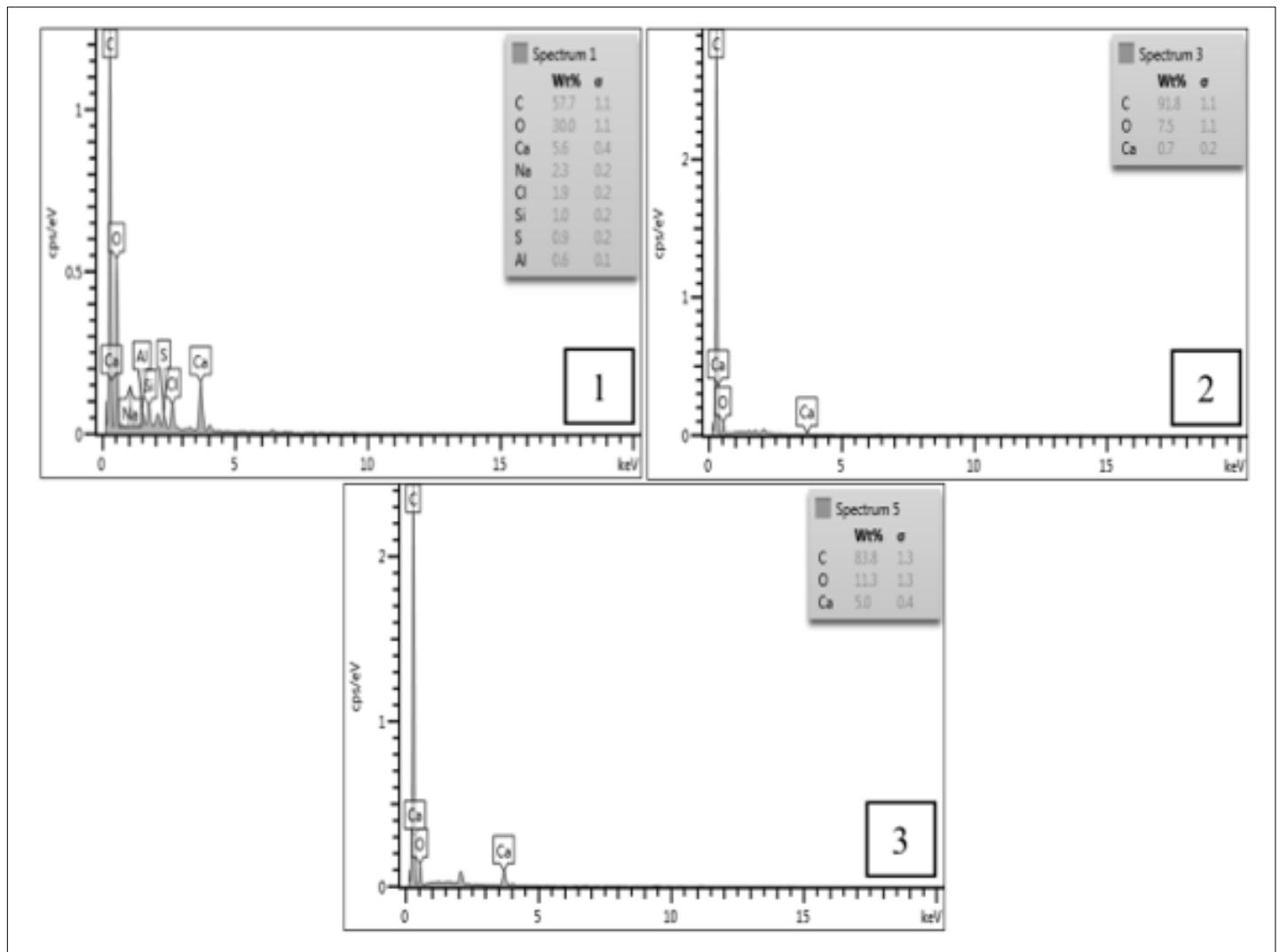

Figure 3. EDX analysis showed the atomic percentage of each element in HDPE Natural plastic flake: 1) Unwashed, 2) cold wash only, 3) cold wash $10 \mathrm{~min}$, and hot wash $10 \mathrm{~min}$ at $95^{\circ} \mathrm{C}$ with added $40 \mathrm{~g} / \mathrm{L}$ calcium carbonate

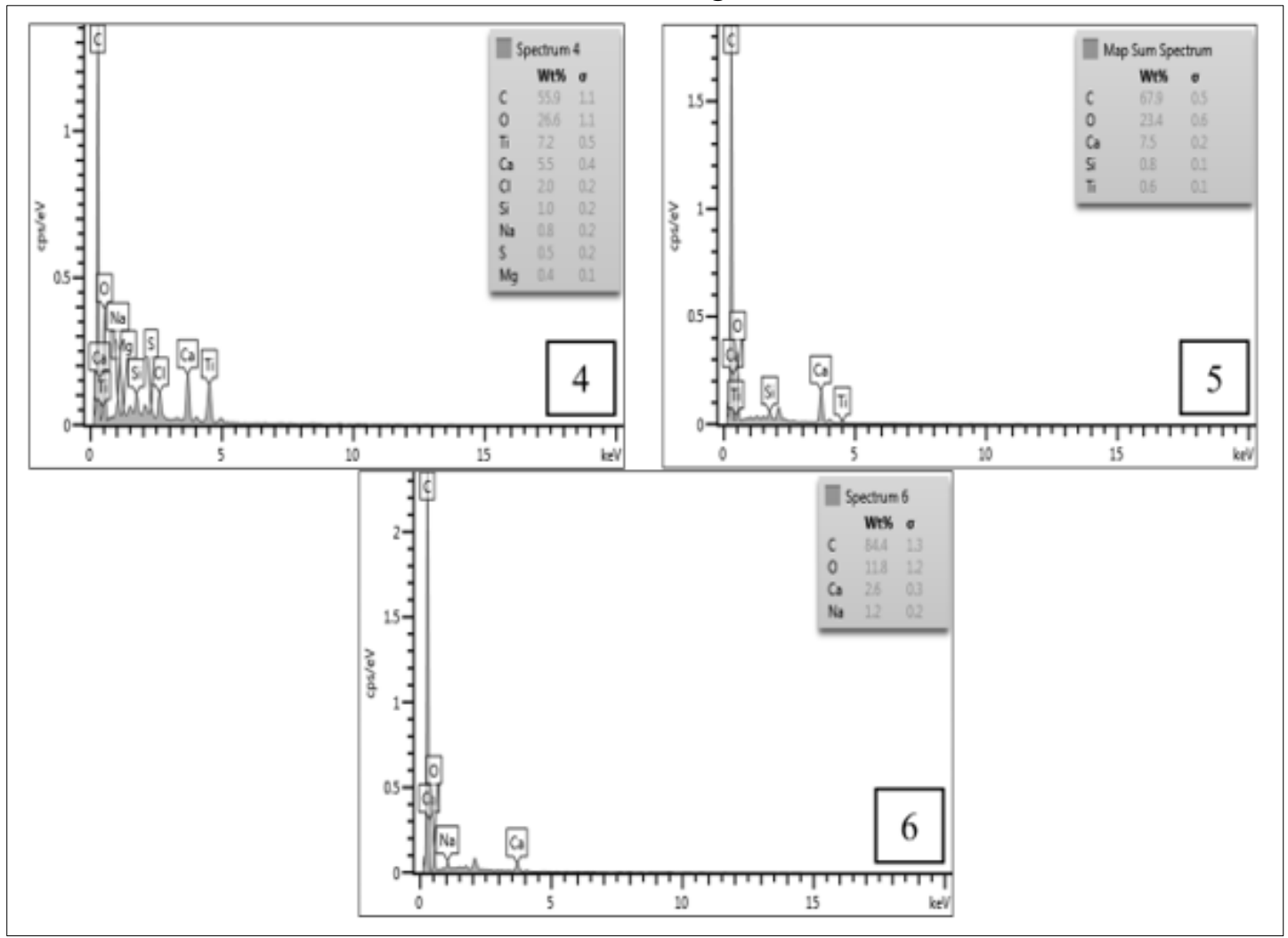

Figure 4. EDX analysis showed the atomic percentage of each element in HDPE Mix flake:

4) Unwashed, 5) cold wash only, 6) cold wash $10 \mathrm{~min}$ and hot wash $15 \mathrm{~min}$ at $95^{\circ} \mathrm{C}$ with added $40 \mathrm{~g} / \mathrm{L}$ sodium bicarbonate 

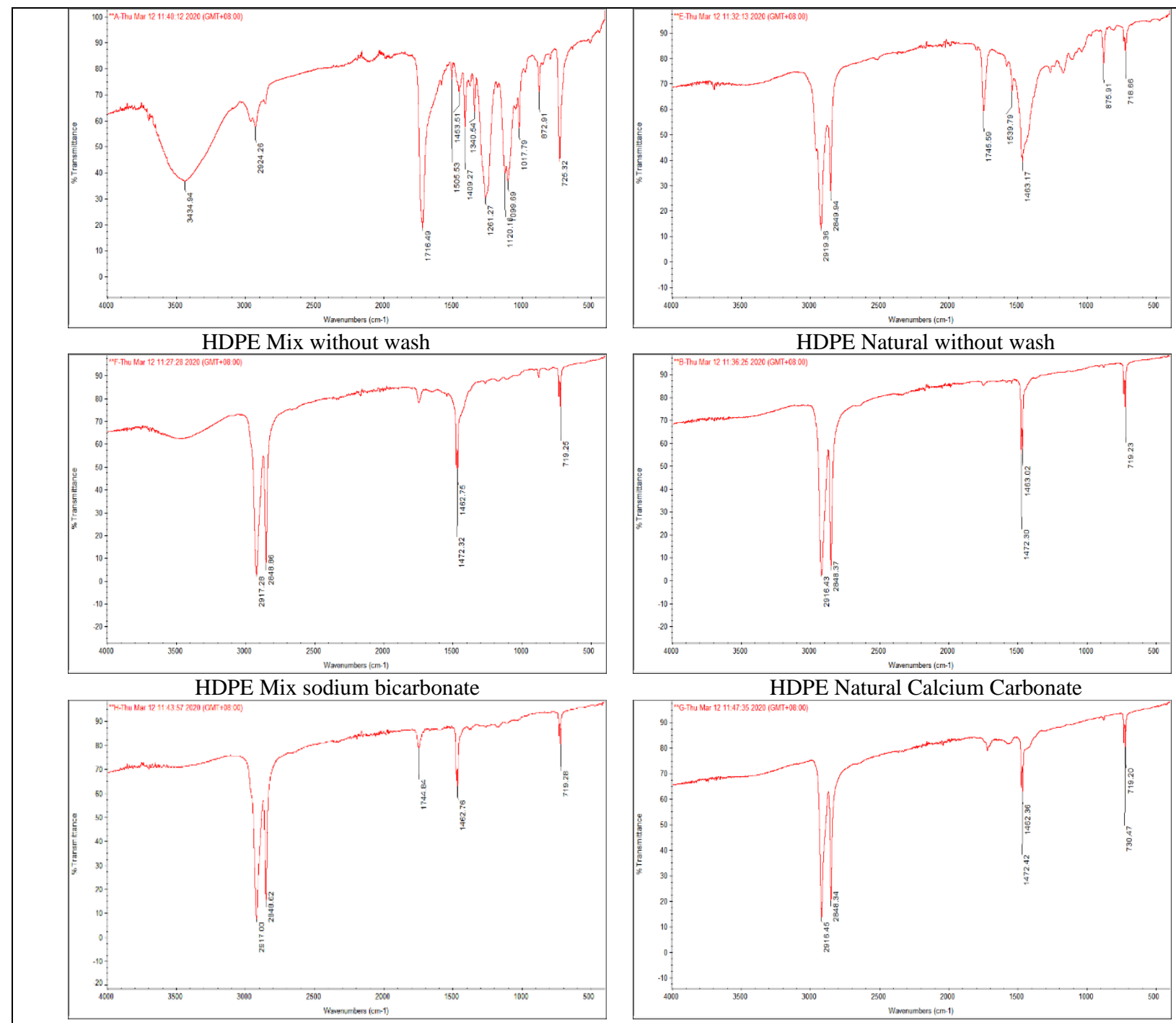

HDPE Mix sodium bicarbonate + citric acid

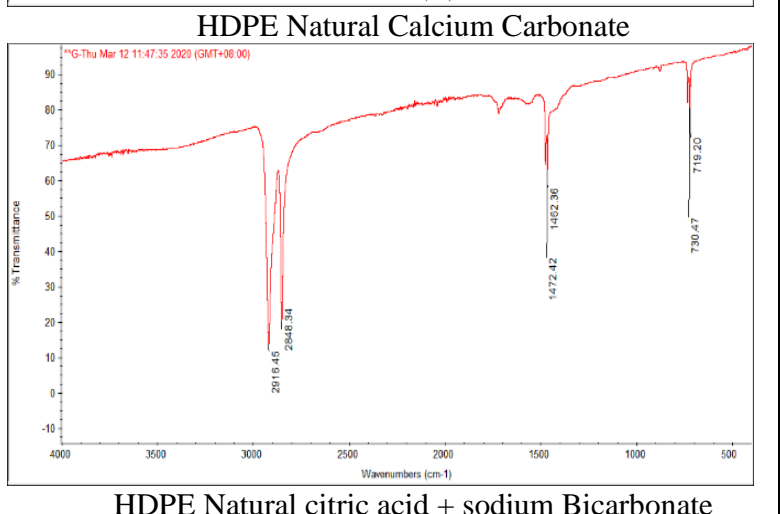

Figure 5. FTIR analysis of selected HDPE plastic samples at conditions

Table 1 reveals that the highest odor control score for HDPE natural was obtained by using the hot washing technique at $95^{\circ} \mathrm{C}$ for $10 \mathrm{~min}$, whereas the highest score for HDPE mix was obtained through hot washing at $95^{\circ} \mathrm{C}$ for $15 \mathrm{~min}$. As inferred from the result, increasing the washing temperature further should have a substantial effect. However, HDPE has melting points that usually range from $120^{\circ} \mathrm{C}$ to $150^{\circ} \mathrm{C}$ [6], and its crystallization temperature is $100^{\circ} \mathrm{C}$. In addition, the most appropriate crystallization temperature for HDPE crystals that are moderately grown on fibers is $100^{\circ} \mathrm{C}$, which is the temperature at which lamellae with the maximum size and uniformity form [7]. Thus, the temperature for washing was regulated to be below the melting point of HDPE.

A longer hot washing time (15 min) was needed to obtain better odor elimination results for HDPE mix plastic than for HDPE natural (10 min). The surface of the HDPE plastic was scattered with various chemicals, mainly volatile organic compounds (VOCs), which are responsible for most odors in synthetic polymers [8]. The removal of VOCs will thus result in odor elimination. Extending the washing time increased the efficiency of the process because adhesives were effectively eliminated. However, after prolonged washing, VOC removal became negligible as emissions decreased [9]. Therefore, washing at $95^{\circ} \mathrm{C}$ for $10-15$ min intervals was sufficient. HDPE mix plastics were more odorous than HDPE natural plastics because they come from various sources that primarily contained detergents, cosmetics, and other materials. Hence, a long hot-washing duration was needed for HDPE mix plastics. 
The hot water temperature of $95^{\circ} \mathrm{C}$ was chosen for the chemical treatment of HDPE natural and HDPE mix for 10 and $15 \mathrm{~min}$. As shown in Table 2, the best results for HDPE mix were achieved through washing with sodium bicarbonate and citric acid; however, calcium carbonate was more effective in washing out the odor of HDPE natural. The FTIR results showed that the peak of HDPE natural after washing with sodium bicarbonate and citric acid was higher than that after washing with calcium carbonate. The HDPE mix exhibited the opposite effects.

As shown in Figure 1 and 2, the surfaces of HDPE natural (A) and HDPE mix (D) without any treatment were rough and coated with dirt and impurities. However, the surface of HDPE Natural (B) became clean and smooth after cold washing. A white residue became evenly distributed on the surface of HDPE natural (C) after hot washing with calcium carbonate. As shown in (E) and (F), the surface of HDPE mix was still rougher compared with that of HDPE natural but showed less dirt after cold and hot washing.

EDX analysis showed that the percentage of each element in both types of recycled HDPE had decreased. EDX analysis revealed that the surfaces of HDPE samples 1 and 4 comprised numerous elements that originated from various chemicals that were retained. Although further cold and hot washing with calcium carbonate at the optimal temperature $(2 \& 3)$ would wash off some chemical compounds that were scattered on the surfaces of HDPE natural, calcium carbonate precipitates would remain (3). Moreover, fewer elements were scattered on (6) than on (5) due to the effectiveness of sodium bicarbonate treatment. The use of chemical material in a hot wash left some compounds with calcium and sodium elements scattered on (3) and (6).

FT-IR was carried out to determine the chemical changes in HDPE samples before and after treatment. The FT-IR result in Figure 5 showed that the characteristic peaks corresponding to the structure of the chemicals reduced significantly when HDPE underwent a series of washes. The peak value of unwashed HDPE natural is shown in Table 3. After chemical treatment, the peaks of the carbonyl compound, hetero-oxy compounds, and ether and oxy compounds reduced. The functional groups of organic components on the surface of HDPE natural are tabulated in Table 3 . The peak values of the unwashed HDPE mix are shown in Table 4. The peaks of aliphatic alkane, aryl group, aliphatic organo-halogen compound, hetero-oxy compounds, inorganic ions, ether, and oxy compound group, aromatic amino, alcohol and hydroxy compound, methyne, aryl group, amine, and amino reduced after chemical treatment.

Table 3. Peaks value of untreated HDPE Natural and corresponded to its characteristics [10]

\begin{tabular}{|c|c|c|}
\hline Wavelength $\mathbf{~ ( m}^{-\mathbf{1}} \mathbf{)}$ & Functional group & Description \\
\hline $2919.36 / 2849.94$ & Aliphatic alkane & Methylene C-H asym. / sym. stretch \\
\hline 1745.59 & Carbonyl compound & Alkyl carbonate and Ester \\
\hline 1539.79 & Hetero-oxy compound & Aromatic nitro compound \\
\hline \multirow{2}{*}{1463.17} & Aliphatic alkane & Cethyl C-H asym. Bend \\
\cline { 2 - 3 } & Inorganic ions & C=C-C stretch \\
\cline { 2 - 3 } & Aryl group & Carbonate ion \\
\hline \multirow{2}{*}{875.91} & Inorganic ions & Aromatic phosphates \\
\cline { 2 - 3 } & Hetero-oxy compound & Peroxides, C-O-O- stretch \\
\cline { 2 - 3 } & Ether and oxy compound & Aliphatic chloro-compound, C-Cl stretch \\
\hline \multirow{2}{*}{718.66} & Organo-halogen compound & Alcohol, OH out-of-plane bend \\
\cline { 2 - 3 } & Alcohol and hydroxy compound & \\
\cline { 2 - 3 }
\end{tabular}

Table 4. Peaks value of untreated HDPE Mix and corresponded to its characteristics [10]

\begin{tabular}{|c|c|c|}
\hline Wavelength $\left(\mathbf{c m}^{-1}\right)$ & Functional group & Description \\
\hline \multirow{2}{*}{725.32} & Organo-halogen compound & Aliphatic chloro-compound, C-Cl stretch \\
\cline { 2 - 3 } & Aliphatic alkane & Methylene $\left(\mathrm{CH}_{2}\right)_{\mathrm{n}}$ rocking \\
\hline \multirow{3}{*}{872.92} & Ether and oxy compound group & Peroxides, C-O-O-stretch \\
\cline { 2 - 3 } & Hetero-oxy compound & Aromatic phosphates \\
\cline { 2 - 3 } & Inorganic ions & Carbonate ion \\
\hline \multirow{2}{*}{1017.79} & Aliphatic alkane & Cyclohexane ring vibration, Skeletal C-C vibrations \\
\cline { 2 - 3 } & Aryl group & Aromatic C-H in-plane bend \\
\hline
\end{tabular}




\begin{tabular}{|c|c|c|}
\hline & Aliphatic organohalogen compound & Aliphatic fluoro compounds, C-F stretches \\
\hline & Hetero-oxy compound & Aliphatic phosphates (P-O-C stretch) \\
\hline & Inorganic ions & Phosphate ion \\
\hline \multirow[t]{3}{*}{1120.16} & Aliphatic alkane & Skeletal C-C vibrations \\
\hline & Ether and oxy compound & $\begin{array}{l}\text { Alkyl-substituted ether, C-O stretch } \\
\text { Cyclic ethers, large rings, C-O stretch }\end{array}$ \\
\hline & Inorganic ions & Sulfate ion \\
\hline \multirow[t]{6}{*}{1261.27} & Ether and oxy compound & Aromatic ethers, aryl O stretch Epoxy \\
\hline & Amino group & Aromatic primary amine, $\mathrm{CN}$ stretch \\
\hline & Alcohol and hydroxy compound & Primary or secondary, $\mathrm{OH}$ in-plane bend \\
\hline & Amino group & Aromatic primary amine, $\mathrm{CN}$ stretch \\
\hline & Alcohol and hydroxy compound & Primary or secondary, $\mathrm{OH}$ in-plane bend \\
\hline & Methyne $(>\mathrm{CH}-)$ & Skeletal C-C vibrations \\
\hline \multirow[t]{4}{*}{1340.54} & Aliphatic alkane & Methyne Bend \\
\hline & Hetero-oxy compound & $\begin{array}{l}\text { Sulfonates, Aromatic nitro compounds, Organic } \\
\text { phosphate ( } \mathrm{P}=\mathrm{O} \text { stretch) }\end{array}$ \\
\hline & Alcohol and hydroxy compound & Phenol or tertiary alcohol \\
\hline & Carbonyl compound & Carboxylate, carboxylic acid salt \\
\hline \multirow[t]{3}{*}{-1409.27} & Alcohol and hydroxy compound & Phenol or tertiary alcohol, $\mathrm{OH}$ bend \\
\hline & $\begin{array}{l}\text { Simple hetero-oxy compound: } \\
\text { Sulfur-oxy compounds }\end{array}$ & Sulfur-oxy compounds-Organic sulfates \\
\hline & Common inorganic ions & Ammonium ion \\
\hline \multirow[t]{2}{*}{1505.53} & Aryl group & $\mathrm{C}=\mathrm{C}-\mathrm{C}$ stretch \\
\hline & Hetero-oxy compound & Aromatic nitro compounds \\
\hline 1716.49 & Carbonyl compound & Carboxylic acid and ketone \\
\hline 2924.26 & Aliphatic alkane & Methyl/methylene asym. stretch \\
\hline \multirow[t]{2}{*}{3434.94} & Alcohol and hydroxy compound & Hydroxy group, H-bonded $\mathrm{OH}$ stretch \\
\hline & Amine and amino compound & Secondary heterocyclic amine stretches \\
\hline
\end{tabular}

The effective chemical compounds in the HDPE mix were the mixture of sodium bicarbonate and citric acid. Baking soda is a weak alkali that can easily dissolve dirt and grease when utilized as a gentle scouring powder in water. It also has unique buffering capabilities. It deodorizes by neutralizing acidic and basic odor molecules, thus creating an odor-free state [11]. Citrate salt is produced through the combination of two chemicals. Alkali metal citrate salts are readily soluble in water. The odors have at least one functional group that could react with citrate salts. This reaction changed the compound structure, resulting in a reduction or loss of the odorous characteristics of HDPE mix [12]. For HDPE natural, calcium carbonate was highly efficient in minimizing offensive odors that contained alcohol because it has high adsorption energy for alcohol groups. It has an affinity for delocalizing charges by ordering the $-\mathrm{OH}$ group end of organic molecules such that molecular $\mathrm{O}$ associates with atomic $\mathrm{Ca}$, whereas $\mathrm{H}$ associates with $\mathrm{CO}_{3}[13]$.

\section{Conclusions}

This research was performed to investigate the usage of chemicals to deodorize HDPE plastics naturally at $95^{\circ} \mathrm{C}$ over a fixed period. Numerous odorants were found to be involved in the odors of the sample and were successfully detected by targeted odorant analysis. This study showed that the causative odorants included a wide variety of complex chemical structures. A mixture of sodium bicarbonate (baking soda) and citric acid exerted significant deodorizing effects on HDPE mix, whereas calcium carbonate demonstrated promising deodorizing effects on HDPE natural. The various sources of HDPE plastics contributed various odorants that affected the effectiveness of particular chemicals in odor reduction. The modified washing method greatly reduced the overall strength of odors. Developing viable concepts for postconsumer HDPE packaging is vital for a circular economy. 
Acknowledgement. The authors would like to thank Ministry of Higher Education Malaysia and Universiti Kebangsaan Malaysia for their financial support under the grant FRGS/1/2018/TK05/UKM/ 02/4 and GUP-2017-041.

\section{References}

1.KEMENTERIAN PERUMAHAN DAN KERAJAAN TEMPATAN, (2011), A Study on Plastic Management in Peninsular Malaysia.

2.WONG, E. K., \& JASMIN, A. F., (2019), Plastic: An Undegradable Problem. Retrieved July 20, 2020, from http://www.krinstitute.org/Views-@-Plastic-; An_Undegradable_Problem.aspx

3.JEONG, S., \& YOO, S., (2017), Preparation and properties of sodium bicarbonate-incorporated LDPE films with deodorising function for kimchi packaging. Packaging Technology and Science, 30(12), 781790. https://doi.org/10.1002/pts.2333

4. ***Anon, (2019), The Science of Febreze . Retrieved July 20, 2020, from https://www.febreze.com/en-us/safety/science-and-chemicals-in-febreze 5.ADAMS, C., (2013), Using Barn Lime. Retrieved July 20, 2020, from https://info.mannapro.com/equine/Using-Barn-Lime-Think-Again-Our-Friend-Sweet-Pea-ExplainsWhy

6.O PALENE, (2016), MSDS of High Density Polyethylene. Retrieved from https://www.opalindia.in/PDF/HDPE/Material Safety Data Sheet_HDPE.pdf

7.MIAO, W., ZHU, H., DUAN, T., CHEN, H., WU, F., JIANG, L., \& WANG, Z., (2018), High-density poly-ethylene crystals with double melting peaks induced by ultra-high-molecular-weight polyethylene fibre. Royal Society Open Science, 5(7), 180394. https://doi.org/10.1098/rsos.180394

8.HODGSON, S. C., CASEY, R. J., BIGGER, S. W., \& SCHEIRS, J., (2000), Review of volatile organic compounds derived from polyethylene. Polymer - Plastics Technology and Engineering, 39(5), 845874. https://doi.org/10.1081/PPT-100101409

9.KREHULA, L. K., SIROCIC, A. P., DUKIC, M., \& HRNJAK-MURGIC, Z. (2012). Cleaning efficiency of poly(ethylene terephthalate) washing procedure in recycling process. Journal of Elastomers and Plastics, 45(5), 429-444. https://doi.org/10.1177/0095244312457798

10.COATES, J., (2006), Interpretation of Infrared Spectra, A Practical Approach. In Encyclopedia of Analytical Chemistry. https://doi.org/10.1002/9780470027318.a5606

11.***Gonneville Inc., (2018), Baking Soda Abrasive. Retrieved July 30, 2020, from https://gonneville.com/baking-soda-abrasive/

12.***Anon, (2013), Citrate Salts for Eliminating Odors. Retrieved July 14, 2020, from https://patentimages.storage.googleapis.com/5b/cc/87/b98f7ffcb666a2/WO2014137350A1.pdf

13.DENIS V., OKHRIMENK O., JOANNA NISSENBAUM, MARTIN PETER ANDERSSON, MATS M.H. OLSSON, S. L. S. S., (2013), Adsorption Energies of Functional Groups to Calcium Carbonate Polymorphs: The Importance of -OH and -COOH groups. Langmuir 29(35): 11062-11073. https://doi.org/10.1021/la402305x

Manuscript received: 15.07 .2021 